\title{
Interactive comment on "Combining Ensemble Kalman Filter and Reservoir Computing to predict spatio-temporal chaotic systems from imperfect observations and models" by Futo Tomizawa and Yohei Sawada
}

Anonymous Referee \#2

Received and published: 27 August 2020

The summary of existing work, novel directions, and discussion of findings is strong.

Some further questions: Does learning the LETFK analysis with a different method (e.g. vanilla feedforward network) give the same result? In other words, is there anything interesting about reservoir computing in particular in this context? Does learning the analysis from some other method work in the same way?

Printer-friendly version

Discussion paper

Interactive comment on Geosci. Model Dev. Discuss., https://doi.org/10.5194/gmd-2020-211, 2020. 